\title{
TÉCNICA DEL ESTUDIO ECOGRÁFICO PARA EL DIAGNÓSTICO DE PIOMETRA EN CANINOS
}

\author{
Harold Agurto R. ${ }^{1}$, Víctor Fernández A. ${ }^{2}$, Rosa Perales C. ${ }^{3}$ y Diego Díaz C. ${ }^{2}$
}

\section{Ultrasound diagnosis of pyometra in dogs}

A total of 21 female dogs, of different breeds and ages, with a clinical history of pyometra, and one apparently normal bitch, were subjected to ultrasound and hematological analysis, as well as macroscopic and histological examination of the uterine horns. Ultrasound analysis proved to be highly accurate for the diagnosis of pyometra in all 21 dogs with clinical symptoms. The uterine horns of these animals were enlarged, and anechogenic and/or hypoechogenic, while in most cases the uterine walls were enlarged and hyperechogenic, with hypoechogenic rough endometrial surfaces, confirming the diagnosis of pyometra. No uterine abnormalities were detected in the apparently normal case.

Key words: Ultrasound, pyometra, hypoechoic

Para la realización de este trabajo se utilizaron 21 caninos hembras de distintas razas y edades, con una historia clínica presuntiva de piometra, cada caso fue evaluado individualmente, demostrándose la utilidad de la ecografía como método nuevo, rápido, no lesivo y altamente confiable para el diagnóstico de esta patología, adicionalmente se tomaron muestras de sangre para hematología, y se procedió a obtener los cuernos uterinos para su evaluación macroscópica e histopatológica. También se evaluó un caso aparentemente normal, tanto clínica, hematológica, ecográfica, macroscópica y microscópicamente. Los hallazgos mostraron en todos los casos crecimiento de ambos cuernos uterinos con la presencia de contenido anecógeno y/o hipoecógeno, una pared uterina engrosada e hiperecógena en la mayoría de los casos, y superficie endometrial rugosa e hipoecógena. El caso aparentemente normal no mostró imagen ecográfica con crecimiento uterino ni contenido.

Palabras claves: Ultrasonido, ecografía, piometra, hipoecoico

\footnotetext{
1 Práctica privada.

${ }^{2}$ Hospital Veterinario - Clínica de Animales Menores. IVITA - FMV-UNMSM

${ }^{3}$ Laboratorio de Histopatología IVITA - FMV - UNMSM.
} 


\section{1\%}

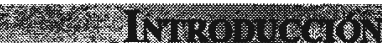

Una de las patologías más comunes en caninos hembras adultas enteras es la Piometra; la cual es primariamente diagnosticada mediante anamnesis y signos clínicos o, en algunos casos mediante exámenes hematológicos, y optan por diagnósticos radiológicos o ultrasonográficos. (Suárez y Martínez, 1999).

En la actualidad, la clínica de animales pequeños, utiliza modernos métodos diagnósticos, que antes sólo eran usados en medicina humana (Instituto Hispanoamericano de Gestión Académica, 1999). Entre estos sistemas de diagnóstico se tiene la: radiología, tomografía, resonancia magnética, radiología intervencionista, ultrasonografía (ecografía). (Organización Mundial de la Salud, 1998).

El presente estudio fue diseñado para evaluar la morfología, tamaño y contenido del útero mediante ecografía de los casos presuntivos de piometra en caninos.

\section{E. MATERITES STOTONOS}

\section{Materiales}

En el presente estudio se utilizaron 21 caninos hembras de diferentes razas y edades; estos animales a la anamnesis, signos clínicos y hematología resultaron con diagnóstico presuntivo de piómetra.

Se utilizó un ecógrafo portátil SONO ACE 600; transductores convexos de doble frecuencia $5 / 6 \mathrm{mhz}$; y 3,5/4 mhz.; impresora ecográfica para papel termosensible; rollo de papel termosensible para imágenes ecográficas; gel de contacto y alcohol. Además, material fotográfico (cámara fotográfica, película fotográfica); material de cirugía; material de fijación y procesamiento histológico; historias clínicas.

\section{Métodos}

Previo al examen ecográfico los animales fueron rasurados en la región abdominal y pélvica, aplicándose gel de contacto y/o alcohol luego se colocó un transductor convexo de 3,5 o 6,0 mhz.

Para la evaluación se ubicó la vejiga, la cual tuvo una moderada cantidad de orina. Adyacente a la vejiga se ubicó el cuerpo del útero y cuernos uterinos, que al estar alterados pudieron ser visualizados en el monitor. El útero fue evaluado tanto en planos sagitales como transversales; su morfología, contenido, diámetro transverso, diámetro antero-posterior, pared uterina, fueron evaluados e impresos en papel termosensible.

Todos aquellos animales en los cuales el estudio ecográfico reveló contenido anecoico o hipoecoico en cuernos uterinos, pasaron a la ovariohisterectomía para la obtención de los cuernos uterinos para su evaluación macroscópica según su morfología, medidas del diámetro transversal y anteroposterior, contenido y medidas de pared uterina.

Se tomaron muestras de cada animal de dos centímetros cuadrados de tejido alterado por cada cuerno, fijándose en formol al $10 \%$, para su procesamiento histopatológico.

Del total de animales con diagnóstico presuntivo de piometra, cuatro pertenecían al grupo de animales jóvenes ( 0 a 2 años), 5 al grupo de animales adultos jóvenes ( 2 a 6 años) y 12 al grupo de los adultos maduros (6 a más años).

Entre los signos clínicos observados en estos animales fueron: depresión ( $20 \mathrm{ca}$ sos) y anorexia (19 casos), que son los signos de mayor presencia, secreción vaginal y polidipsia en 13 de los casos, vómitos en 8 casos, estreñimiento en 5 casos, diarrea en 4 casos, y poliuria en 3 casos y un promedio de temperatura de $39^{\circ} \mathrm{C}$. Del total de animales, 19 casos tuvieron un celo previo a la pre- 
sentación del cuadro clínico; 2 casos tuvieron historia de aplicación hormonal en las semanas previas al inicio de los signos clínicos, en 13 animales se observó una secreción vaginal; 10 animales presentaron distensión abdominal; en 5 se pudo evidenciar una masa intraabdominal y 14 presentaron deshidratación en diferentes grados.

Las evaluaciones ecográficas presentaron: en dos casos imágenes uterinas uniformes, una de forma redondeada (Figura 1) y la otra de forma tubular (Figura 2), 19 de los casos presentaron en corte longitudinal imágenes tubular-ampuliformes (Figura 3) y en sus cortes transversales imágenes circulares (Figura 4); de estos 19 casos, en 14 casos también se observó tanto en cortes transversales y sagitales, dos a más secciones de los cuernos uterinos de forma circular y de diferentes diámetros (Figura 5).

Además, en las evaluaciones de las imágenes ecográficas se tomaron medidas de los cuernos uterinos con contenido, en tres zonas distintas de acuerdo a su posición anatómica: anterior, medio y posterior, y en sus diámetros anteroposterior y transversal y tanto en sus planos sagitales como transversales, obteniendo sus promedios como datos referenciales, y obteniendo una medida mínima de $12 \mathrm{~mm}$ de diámetro antero-posterior, y una medida máxima de $61 \mathrm{~mm}$ en un diámetro transversal.

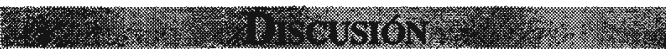

En esta alteración los animales presentan uno o más signos clínicos sugestivos de piometra, pero no demuestran en definitiva la presencia de la piometra. (Kirk y Bonagura. 1994). Lo que fue corroborado en el trabajo, donde los animales presentaron todos o algunos de estos signos sugestivos de piometra como depresión, anorexia, secreción vaginal, polidipsia, vómitos; promedio corporal de la temperatura $39^{\circ} \mathrm{C}$ como lo indica Ettinger (1992), que señala que la temperatura rectal usualmente es normal en los casos de piometra.
- Los signos clínicos presentados en los animales fueron, secreción vaginal (13 casos), distensión abdominal (10 casos), masa abdominal (5 casos), deshidratación (14 casos); estos signos orientan a un diagnóstico presuntivo de piometra (Ettinger, 1992), este último autor señala que en la exploración física se advierte deshidratación de intensidad variable; pudiendo o no haber una exudación vaginal purulenta que puede contener sangre; y el útero por lo común es grande y palpable y que depende del volumen de la colecta.

Los datos de anamnesis, signos clínicos, hematología orientan al diagnóstico presuntivo de piometra, y no es adecuado dar un diagnóstico definitivo de la enfermedad basándose solamente en ello. Suárez y Martínez (1999), afirman que la piometra es una metropatía potencialmente riesgosa para la vida; su presentación clínica y hematológica es variada, y es por todo esto que el ultrasonido cobra un enorme valor en su diagnóstico, debido a que se descarta definitivamente el aumento del volumen de los cuernos uterinos.

Fritsch y Gerwing (1996), reportan que un punto importante en el estudio ecográfico es la posición del transductor, para obtener cortes transversales, longitudinales y oblicuos de los cuernos. Goddard (1995), manifiesta que el útero tiene un diámetro incrementado y se puede doblar sobre si mismo de tal manera que dos o más secciones de cada cuerno puedan ser tomadas en el mismo plano. Además en cortes transversales aparecen formaciones redondeadas, cuyo diámetro oscila entre pocos milímetros hasta llegar a ocupar todo el abdomen (Fritsch y Gerwing, 1996). Estos datos se corroboran con los resultados obtenidos, los cuales indican morfología variada de los cuernos uterinos, tal como se representan en las Figuras 1, 2, 3, 4 y 5.

De acuerdo al trabajo realizado por Suárez y Martínez (1999), observaron presentaciones ecográficas variables, en la ma- 


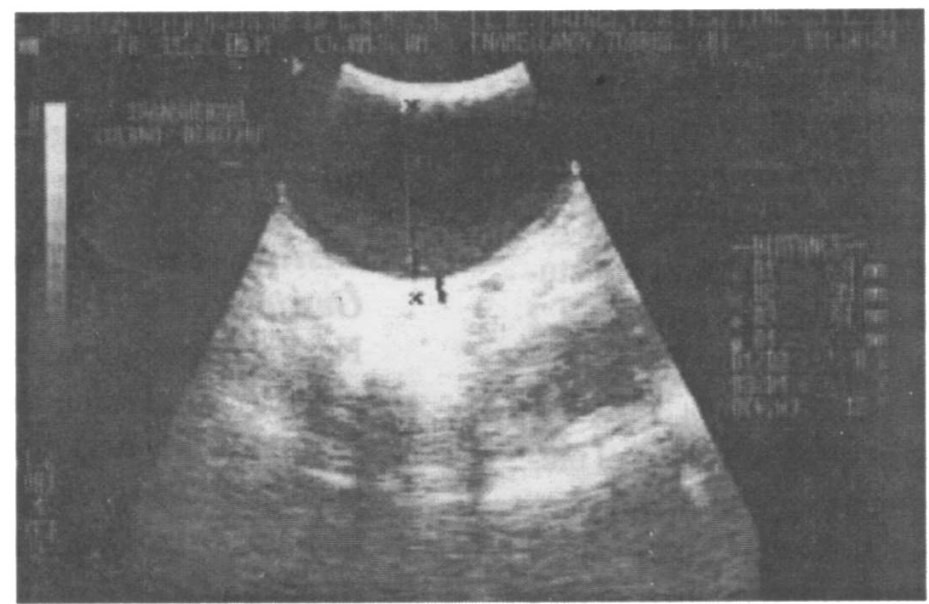

Figura 1. Imagen redondeada uniforme anecogénica. Corte transversal.

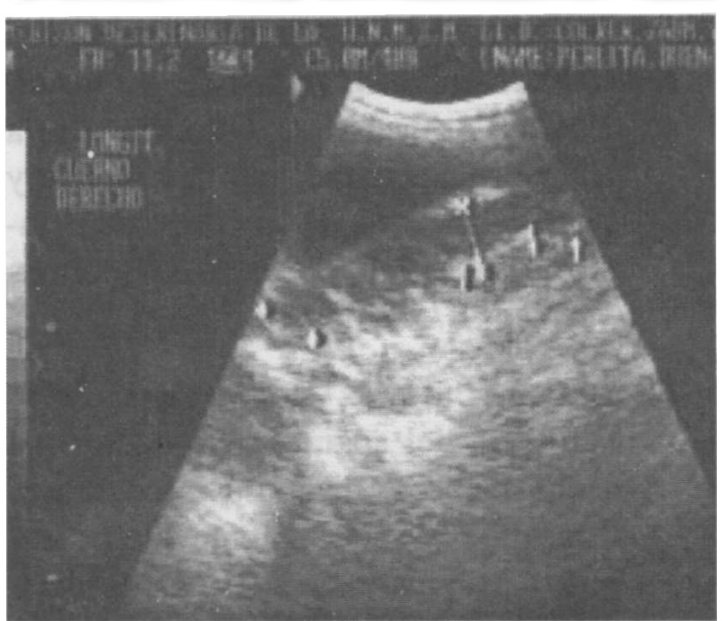

Figura 2. Imagen uniforme tubular hipoecogénica Corte longitudinal.

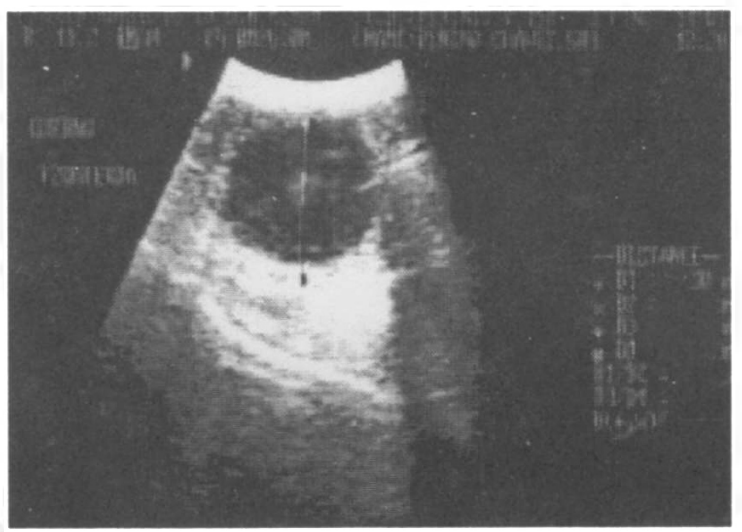

Figura 4. Imagen circular hipoecogénica. Corte transversal.

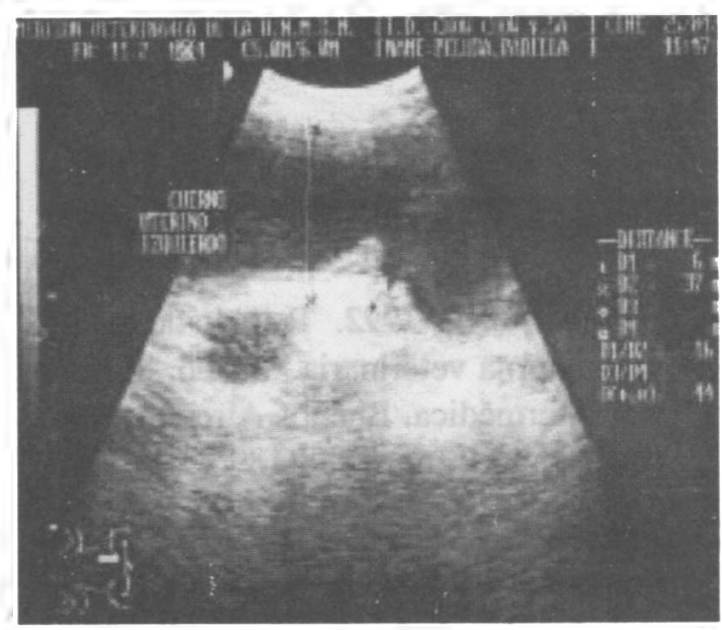

Figura 3. Imagen tubular ampuliforme anecogénica. Corte longitudinal.

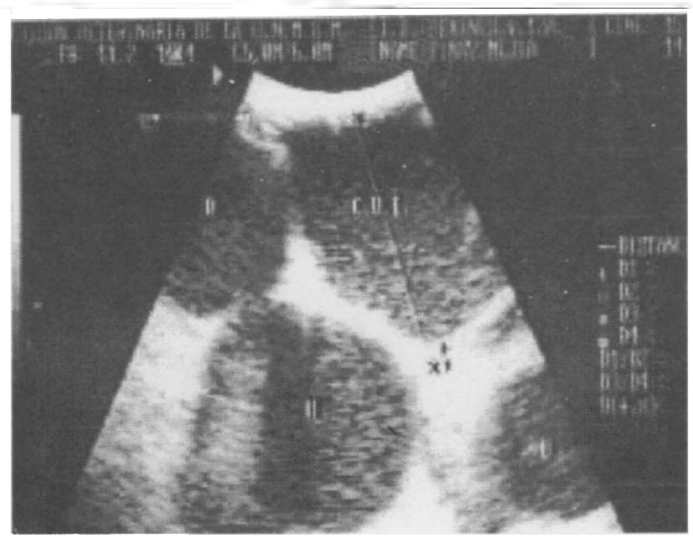

Figura 5. Cuatro imágenes circulares hipo y anecogénicas en un mismo corte corte transversal. 
yoría de pacientes se observó contenido uterino bilateral, los diámetros que encontró oscilaron entre 1 y 7 centímetros, mientras que la pared uterina presentó grados variables de espesor. Datos que se asemejan a los obtenidos por ecografía en el presente estudio, donde los diámetros oscilaron entre 1.2 cm y $6.1 \mathrm{~cm}$.

Si la distensión no es marcada, el útero lleno de líquido puede ser confundido con asas intestinales; sin embargo el útero carece de peristaltis, cuando el diámetro del útero es mayor que el del intestino delgado, el diagnóstico es más simple. Habitualmente se aumenta la imagen ecográfica del útero cuando contiene grandes volúmenes de líquido. (Goddard, 1995).

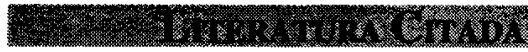

1. Ettinger, S. J. 1992. Tratado de medicina interna veterinaria. 3a. ed., Editorial Intermédica. Buenos Aires, Argentina, Tomo II, pp. 1888-1895.

2. Fritsch R. y M. Gerwing. 1996. Ecografía de Perros y Gatos. 1a. ed. Editorial Açribia S.A. Zaragoza, España, p. 233.
3. Goddard, P. J. 1995. Ecografía Veterinaria. Editorial Acribia, S.A.; Zaragoza, España, 387 páginas, pp. 25-30; $65-$ 69.

4. Instituto Hispanoamericano de Gestión Académica. 1999. I Curso Nacional Integral de Ecografía Ginecoobstétrica. Física de Ultrasonido y Ecografía de Abdomen. Universidad Nacional "San Luis Gonzaga de Ica"Instituto Hispanoame-ricano de Gestión Académica.

5. Kirk, R. W. y J. O. Bonagura. 1994. Medicina Interna. 1a. ed., p. 1073-1076. Editorial McGraw-Hill-Interamericana, Madrid, España.

6. Organización Mundial de la Salud. 1998. Formación en Ultrasonografía Diagnóstica: Fundamentos, principios y Normas. Informe de un Grupo de Estudio de la OMS. OMS, Serie de Informes Técnicos 875. Ginebra, p. 51.

7. Suárez M. A. y G. M. Martinez. 1999. Patología del aparato reproductor del canino hembra y diagnóstico ecográfico. Consultor Privado. Montevideo, Uruguay. Miembros de AEVEDI (asociación de especialistas veterinarios en diagnóstico por imagen). 